\section{OP0064 GENETIC MARKERS FOR THE EFFICACY OF TNF BLOCKING THERAPY OF RHEUMATOID ARTHRITIS}

${ }^{1} \mathrm{~L}$ Padyukov, ${ }^{1} \mathrm{~J}$ Lampa, ${ }^{2} \mathrm{M}$ Heimbürger, ${ }^{2} \mathrm{~S}$ Ernestam, ${ }^{3} \mathrm{~T}$ Cederholm, ${ }^{4} \mathrm{I}$ Lundkvist, ${ }^{5} \mathrm{P}$ Andersson, ${ }^{1} \mathrm{Y}$ Hermansson, ${ }^{1} \mathrm{~A}$ Harju, ${ }^{6} \mathrm{O}$ Olerup, ${ }^{1} \mathrm{~L}$ Klareskog, ${ }^{2} \mathrm{~J}$ Bratt. ${ }^{1}$ Rheumatology Unit, Karolinska Hospital, Stockholm, Sweden; ${ }^{2}$ Department of Rheumatology, Huddinge Hospital, Karolinska Institutet, Stockholm, Sweden; ${ }^{3}$ Department of Geriatrics, Stockholm, Sweden; ${ }^{4}$ Clinical Research Center, Stockholm, Sweden; ${ }^{5}$ Center for Inflammation and Hematology Research, Stockholm, Sweden; ${ }^{6}$ Department of Clinical Immunology, Stockholm, Sweden

\subsection{6/annrheumdis-2001.97}

\section{Background}

Objectives The regulation of cytokine production on the level of the gene transcription may involve several types of polymorphisms in promoter/enhancer region. The aim of this study was to evaluate if polymorphism in several genes could associate with the responsiveness to TNF blocking therapy with etanercept $\left(\right.$ Enbrel $\left.^{\circledR}\right)$ in patients with rheumatoid arthritis from Eastern Sweden.

Methods 124 patients with active RA were treated with subcutaneous etanercept $25 \mathrm{mg}$ twice a week. The efficacy measures included ACR and DAS28 response rates after treatment for 3 months. The ?308 TNFA, -1082 IL10 and codon 25 TGFB1 gene polymorphisms were detected by combination of PCR and restriction endonuclease mapping. VNTRs in intron 2 of IL1RN gene were detected by PCR and HLA-DQB1 and HLA-DRB1 were typed and subtyped by PCR-SSP.

Results 24 patients (19\%) were non-responders according to both ACR and DAS28 criteria. We found significant association of one group, composite of TNF1/TNF1 and G/G genotypes, with positive responsiveness to etanercept $(p<0.05)$. Non-responders with TNF2 allele had relatively low ESR before treatment (mean $\pm \mathrm{SE}=25 \pm 5 \mathrm{~mm} / \mathrm{min}$ ) in comparison with other groups $(\mathrm{p}<0.05$, Fisher's PLSD). Individuals with non-shared epitope genes showed approximately 2 times more frequent fail of the therapy if ACR criteria was used.

Conclusion We find strong evidence for association of certain genetic markers with efficacy of etanercept treatment in RA patients. Combined ?308 TNFA and ?1082 IL10 genotype may predispose for the response to etanercept therapy, while ?308 TNFA genotype in combination with ESR may be used for the selection of potential non-responders. These results may provide information for future improvement of treatment of RA.

\section{OP0089 ASSOCIATION BETWEEN TNF -308A AND SYSTEMIC LUPUS ERYTHEMATOSUS IN RELATION TO HLA-DR3 AND SIX MICROSATELLITE MARKERS ON THE SHORT ARM OF CHROMOSOME VI}

${ }^{1} \mathrm{MW}$ Van der Linden, ${ }^{2} \mathrm{~A}$ Van der Slik, ${ }^{3} \mathrm{E}$ Pieterman, ${ }^{2} \mathrm{E}$ Zanelli, ${ }^{2} \mathrm{MJ}$ Giphart, ${ }^{3} \mathrm{FC}$ Breedveld, ${ }^{4}$ RG Westendorp, ${ }^{3} \mathrm{TW}$ Huizinga. ${ }^{1}$ Clinical Epidemiology; ${ }^{2}$ Immunohaematology and Blood Transfusion; ${ }^{3}$ Rheumatology; ${ }^{4}$ General Internal Medicine, Leiden University Medical Centre, Leiden, Netherlands

\subsection{6/annrheumdis-2001.98}

Background Allelic imbalance at polymorphic loci within the human HLA-DRB1 and TNF genes has been observed in association with increased susceptibility to systemic lupus erythematosus.

Objectives We investigated whether the association of HLADRB1*0301 (HLA-DR3) and TNF-308A with SLE could be attributed to linkage to six polymorphic microsatellites between HLA-DRB1 and HLA-C.

Methods Ninety-one consecutive Caucasian patients with SLE and 253 controls (organ donors) were typed for HLA-DRB1, D6S1014, D6S273, TNFa, MIB, C-1-2-5 and C-1-3-2 and for TNF promoter polymorphisms. Independent contribution of alleles to disease susceptibility was estimated by crosstabulation and multivariate regression.

Results Carriership of TNF-308A was associated with susceptibility to SLE (odds ratio [95\% confidence interval], 3.70 [2.246.11]). This remained present after stratification on carriership of HLA-DR3 (pooled odds ratio, 2.53 [1.37-4.70]). Stratification further revealed a possible association of carriership of C-1$2-5 * 192$ with protection from SLE beyond the effects of HLADR3 and TNF-308A. Gene dose effect was observed for -308A only (homozygotes, 7.75 [3.01-20.0], heterozygotes, 3.15 [1.855.37]). In multivariate analysis, the association between HLADR3, TNF-308A, and C-1-2-5*192 remained independently associated with susceptibility to SLE (2.58 [1.29-5.18], 2.76 [1.43-5.31], and 0.26 [0.10-0.66], respectively).

Conclusion An association of carriership of TNF-308A with susceptibility to SLE can not be attributed to linkage to HLA-DR3, nor to other polymorphic markers in the vicinity of the TNF gene. Further loci that are independently associated with SLE might be located in the vicinity of marker C-1-2-5.

\section{OP0091 DIFFERENCES IN DISEASE EXPRESSION IN ADJUVANT ARTHRITIS OF LEWIS RATS INDUCED BY MYCOBACTERIA OR LIPOIDAL AMINE}

U Feige, C King, YL Hu, A Koch, D Duryea, B Bolon. Pharmacology/Pathology, Amgen, Thousand Oaks, USA

\subsection{6/annrheumdis-2001.99}

Background Marked polyarthritis is induced in male Lewis rats by injection of either heat-killed Mycobacterium tuberculosis in mineral oil (AdA) or lipoidal amine in complete Freund's adjuvant (LA/CFA). For both models, paw swelling and body weight loss occur in all rats by 10 to 12 days after immunisation.

Objectives Interestingly, however, the present study demonstrates that the morphologic and densitometric changes of AdA and LA/ CFA are distinguishable.

Methods We induced AdA or LA/CFA in male Lewis rats $(180 \mathrm{~g})$ and evaluated both clinical (body and spleen weight, volume of the tibiotarsal [hock] joints) and morphologic changes (bone mineral density [BMD] by DEXA; histopathologic lesions in the hock and femorotibial [knee] joints). Readings were obtained at the day of onset (as determined by initial paw swelling) as well as 5, 10 and 25 days after onset.

Results Paw swelling, loss of body weight, enhanced spleen weight were identical in AdA and LA/CFA. In contrast, hock inflammation score, hock erosion score and hock cartilage score

\begin{tabular}{llll} 
Abstract OP0091 Table 1 & & \\
\hline & Control & AdA & LA/CFA \\
\hline Hock BMD & $100 \%$ & $87.5 \%$ & $99.9 \%^{*}$ \\
Knee inflammation score & 0 & $3.3 \pm 0.5$ & $2.2 \pm 0.4^{* * *}$ \\
Knee Erosion score & 0 & $3.2 \pm 1.2$ & $1.7 \pm 1.0^{* * *}$ \\
\hline
\end{tabular}

*not different from control, ${ }^{* * *}$ different from AdA (Newman Keuls post hoc test). 